\title{
KEKOMUTATIFAN PADA GRUP PERMUTASI
}

\author{
NEWTON \\ Program Studi Matematika, \\ Fakultas Matematika dan Ilmu Pengetahuan Alam, Universitas Andalas, \\ Kampus UNAND Limau Manis Padang, Indonesia, \\ newton998@yahoo.co.id
}

\begin{abstract}
Some research about cycle permutations and disjoints on cycle nonempty sets has been posted in some papers. However, the degree of the generalization of this result is varies. In this paper we studied the notion disjoint to be applied in arbitrary collections of permutations on arbitrary nonempty sets.
\end{abstract}

Kata Kunci: Permutation groups, commutativity

\section{Pendahuluan}

Pada bagian ini diberikan beberapa definisi dari permutasi, $\operatorname{Sym}(S), S_{n}$, cycle dan permutasi.

Definisi 1.1. [3] Jika $S$ adalah himpunan tak kosong, maka permutasi (simetri) $\alpha$ pada $S$ adalah pemetaan satu-satu dan pada, $\alpha: S \rightarrow S$. Himpunan semua permutasi pada $S$ dinotasikan dengan $\operatorname{Sym}(S)$. Jika $S$ berhingga dengan orde $n$ maka $\operatorname{Sym}(S)$ ditulis dengan $S_{n}$, dan $\operatorname{Sym}(S)$ disebut sebagai himpunan dari permutasipermutasi pada $n$ buah elemen. Dalam hal ini $S$ dapat direpsesentasikan sebagai $S=\left\{a_{k}\right\}_{k=1}^{n}$.

Jika $n$ adalah bilangan bulat positif, maka permutasi $\alpha \in \operatorname{Sym}(S)$ adalah siklik dengan panjang $n$ jika dan hanya jika ada subhimpunan hingga $\left\{a_{i}\right\}_{k=1}^{n}$ dari $S$ sedemikian sehingga $\alpha\left(a_{i}\right)=a_{i+1}$ untuk, $1 \leq i \leq n-1, \alpha\left(a_{n}\right)=a_{1}$ dan $a(x)=x$ untuk setiap $x \in S-\left\{a_{i}\right\}_{i=1}^{n}$. Dalam hal ini dapat ditulis $\alpha=\left(a_{1}, a_{2}, \cdots, a_{n}\right)$. Pemetaan identitas pada $S$ dinotasikan dengan $1_{s}$.

Jika $\operatorname{Sym}(S)$ dioperasikan dengan komposisi fungsi maka akan terbentuk grup disebut grup permutasi pada $S$. Untuk itu perlu konsep titik tertentu, yang dapat dilihat dari definisi berikutnya.

Definisi 1.2. [3] Misalkan $S$ adalah himpunan tak kosong, $p, q \in S$ dan $\alpha \in$ $\operatorname{Sym}(S)$. Maka $p$ adalah titik tetap dari $\alpha$, jika dan hanya jika $\alpha(p)=p ; q$ adalah titik transient (titik sementara) dari $\alpha$ jika dan hanya jika $\alpha(q) \neq q$. Himpunan dari titik tetap dari $\alpha$ adalah $F_{\alpha}=\{x \in S \mid \alpha(x)=x\}$. Sebaliknya himpunan dari titik transient (titik sementara) dari $\alpha$ adalah $T_{\alpha}=\{x \in S \mid \alpha(x) \neq x\}$.

Untuk setiap $\alpha \in \operatorname{Sym}(S), S-F_{\alpha}=T_{\alpha}$ dan $S-T_{\alpha}=F_{\alpha}$. Akibatnya, jika $F_{\alpha}$ dan $T_{\alpha}$ tidak kosong maka $F_{\alpha}$ dan $T_{\alpha}$ tidak kosong $\left\{F_{\alpha}, T_{\alpha}\right\}$ partisi $S$. Untuk lebih jelasnya lihat Proposisi 1.3 berikut. 
Proposisi 1.3. [3] Misalkan $\alpha \in \operatorname{Syms}(S)$.

(1) $F_{\alpha}$ dan $T_{\alpha}$ adalah himpunan yang merupakan komplemen untuk suatu sama lain yang relative pada $S$.

(2) Jika $F_{\alpha}$ dan $T_{\alpha}$ tidak kosong, maka $\left(F_{\alpha}, T_{\alpha}\right)$ adalah partisi dari $S$.

Bukti.

(1) Ini sudah jelas dari Definisi 1.2 bahwa $F_{\alpha} \subseteq S$ dan $T_{\alpha} \subseteq S$. Selanjutnya untuk setiap $x \in F_{\alpha}$, jika dan hanya jika $\alpha(x)=x$ dan jika dan hanya jika $x \notin T_{\alpha}$.

(2) Hasil telah ditunjukkan oleh bagian (1).

Teorema 1.4. [3] Misalkan $\alpha \in \operatorname{Sym}(S)$ dan $x \in S$.

(1) Jika $x \in F_{\alpha}$ maka $\alpha^{n} \in F_{\alpha}$ untuk setiap bilangan bulat $n$

(2) Sebaliknya, jika $\alpha^{n}(x) \in F_{\alpha}$ untuk suatu bilangan $n$, maka $x \in F_{\alpha}$

(3) Jika $\alpha^{n} \in F_{\alpha}$ untuk beberapa bilangan bulat $n$, maka $\alpha^{n}(x) \in F_{\alpha}$ untuk setiap bilangan bulat $n$.

\section{Bukti.}

(1) Jika $x \in F_{\alpha}$, maka $\alpha(x)=x$ (gunakan definisi 2). Jadi untuk setiap bilangan bulat $n$

$\alpha^{n}(x) \in S, \operatorname{dan} \alpha\left[\alpha^{n}(x)\right]=\alpha^{n+1}(x)=\alpha^{n}[\alpha(x)]=\alpha^{n}(x)$.

Oleh karena $\alpha^{n}(x) \in F_{\alpha}$ (Gunakan definisi 2).

(2) Jika $\alpha^{n}(x) \in F_{\alpha}$ untuk beberapa bilangan bulat $n$ maka $\alpha\left[\alpha^{n}(x)\right]=\alpha^{n}(x)$ menurut definisi 2. Selanjutnya $\alpha^{-n}=\left(\alpha^{n}\right)^{-1} \in \operatorname{Sym}(S)$.

(3) Jika $\alpha^{n}(x) \in F_{\alpha}$ untuk beberapa bilangan bulat $n$, maka $x \in F_{\alpha}$ merupakan bagian (2). Karena $x \in F_{\alpha}$ maka $\alpha^{n}(x) F_{\alpha}$ untuk setiap bilangan bulat $n$ untuk bagian (1).

Titik sementara memiliki sifat analog pada Teorema 1.4 untuk titik tetap, di lain pihak dalam menyusun sifat, kita gunakan Proposisi 1.3.

Proposisi 1.5. [3] Misalkan $\alpha \in \operatorname{Sym}(S)$ dan $x \in S$.

(1) Jika $x \in T_{\alpha}$ maka $\alpha^{n}(x) \in T_{\alpha}$ untuk setiap bilangan bulat $n$.

(2) Sebaliknya, jika $\alpha^{n}(x) \in T_{\alpha}$ untuk beberapa bilangan $n$, maka $x \in T_{\alpha}$

(3) Jika $\alpha^{n}(x) \in T_{\alpha}$ untuk beberapa bilangan bulat $n$, maka $\alpha^{n}(x) \in T_{\alpha}$ untuk setiap bilangan bulat $n$.

\section{Bukti.}

(1) Jika $x \in T_{\alpha}$, gunakan Proposisi 1.3. Oleh karena itu $\alpha^{n}(x) \notin F_{\alpha}$ untuk setiap bilangan bulat $n$. Ini merupakan kontrapositif dari Teorema 1.4(2). Karena $x \in T_{\alpha}$ untuk setiap bilangan bulat $n$, berdasarkan Proposisi 1.3.

(2) Jika $\alpha^{n}(x) \in T_{\alpha}$ untuk beberapa bilangan bulat $n$ maka $\alpha^{n}(x) \notin F_{\alpha}$ menggunakan Proposisi 1.3. Selanjutnya $x \notin F_{\alpha}$ kontraposisi dari Teorema 1.4(1) karena $x \in T_{\alpha}$. 
(3) Jika $\alpha^{n}(x) \in T_{\alpha}$ untuk beberapa bilangan bulat $n$, karena $x \in T_{\alpha}$ maka $\alpha^{n}(x) \in$ $T_{\alpha}$ untuk setiap bilangan bulat $n$.

Proposisi 1.6. [3] Misalkan $\alpha \in \operatorname{Sym}(S)$ dan $x \in S$, maka berlaku

(1) $x \in F_{\alpha}$ jika dan hanya jika $\alpha(x) \in F_{\alpha}$.

(2) $x \in T_{\alpha}$ jika dan hanya jika $\alpha(x) \in T_{\alpha}$.

\section{Bukti.}

(1) Jika $x \in F_{\alpha}$ maka $\alpha(x) \in F_{\alpha}$ gunakan Teorema 1.3 (1) Pilih $n=1$ berarti $\alpha(x) \in F_{\alpha}$. Sebaliknya jika, maka $x \in F_{\alpha}$.

Dari Teorema $1.3(2)$ untuk $n=1$.

(2) Jika $x \in T_{\alpha}$ maka $\alpha(x) \in T_{\alpha}$, berdasarkan Proposisi 1.4 (1) berati $\alpha(x) \in T_{\alpha}$ untuk setiap bilangan bulat $n$. Pilih $n=1$ berarti $\alpha(x) \in T_{\alpha}$

Selanjutnya akan dilihat definisi permutasi disjoint, cycle dan permutasi grup sebagai berikut.

Definisi 1.7. [3] Misalkan $\alpha, \beta \in \operatorname{Sym}(S)$. Maka $\alpha$ dan $\beta$ adalah dijoint jika dan hanya jika $T_{\alpha} \cap T_{\beta}=\emptyset$. Khususnya, jika $\alpha=\left(a_{1}, \cdots, a_{k}\right)$ dan $\beta=\left(b_{1}, \cdots, b_{m}\right)$ adalah siklik-siklik di $\operatorname{Sym}(S)$, maka $\alpha$ dan $\beta$ adalah disjoint jika dan hanya jika $a_{i} \neq b_{j}$ untuk setiap $i$ dan $j$ sedemikian sehingga $1 \leq i \leq k$ dan $1 \leq j \leq m$. Sebuah koleksi $C$ dari permutasi-permutasi di $\operatorname{Sym}(S)$ merupakan disjoint jika dan hanya jika $\alpha$ dan $\beta$ adalah disjoint untuk setiap $\alpha, \beta \in C$, yang mana $\alpha \neq \beta$.

Bagian akhir dari Definisi 1.7 menimbulkan pernyataan ada atau tidak sebuah permutasi yang dapat disjoint dengan sendirinya. Artinya jika $S$ adalah sebuah himpunan tak kosong dan $\alpha \in \operatorname{Sym}(S)$.

Proposisi 1.8. [3] Misalkan $\alpha \in \operatorname{Sym}(S)$. Maka $\alpha$ adalah disjoint dengan dirinya sendiri (artinya $\alpha$ dan $\alpha$ adalah dijoint) jika dan hanya jika $\alpha=1_{\text {s. }}$.

Bukti. Karena $1_{s}(x)=(x)$ untuk setiap $x \in S$ atau $F_{1_{s}}=S$, gunakan Definisi 1.2 , sehingga $T_{\alpha}=T_{1_{s}}=\emptyset$. Selanjutnya tentu $T_{1_{s}} \cap T_{1_{s}}=\emptyset$. Menurut Definisi 1.6 hal ini berarti $\alpha$ disjoint dengan dirinya sendiri.

Hasil kekomutatifan untuk permutasi ditemukan dalam Teorema 1.9 berikut.

Teorema 1.9. [3] Misalkan $\alpha, \beta \in \operatorname{Sym}(S)$. Jika $\alpha, \beta$ adalah disjoint maka $\alpha \beta=$ $\beta \alpha$.

Bukti. Misalkan $\alpha$ dan $\beta$ adalah permutasi disjoint di $\operatorname{Sym}(S)$. Berarti $T_{\alpha} \cap T_{\beta}=\emptyset$. Untuk setiap $x \in S$, berlaku salah satu dari

(1) $x \in T_{\alpha}$

(2) $x \in T_{\beta}$

(3) $x \in S-\left(T_{\alpha} \cup(T \beta)\right.$ 
Catat bahwa $S-\left(T_{\alpha} \cup(T \beta)=\left(S-T_{\alpha}\right) \cap\left(S-T_{\beta}\right)=F_{\alpha} \cap F_{\beta}\right.$, menurut Proposisi 1.3. Untuk menunjukkan bahwa, jika $\alpha$ dan $\beta$ disjoint maka $\alpha \beta=\beta \alpha, \forall x \in S$, maka harus ditunjukkan bahwa hal ini berlaku untuk ketiga kemungkinan tersebut.

(1) Untuk $x \in T_{\alpha}$ berlaku $(\alpha \beta)(x)=(\beta \alpha)(x)$

(2) Untuk $x \in T_{\beta}$ berlaku $(\alpha \beta)(x)=(\beta \alpha)(x)$

(3) Untuk $x \in F_{\alpha} \cap F_{\beta}$ berlaku $(\alpha \beta)(x)=(\beta \alpha)(x)$

Selanjutnya lihat Proposisi 1.10 berikut.

Proposisi 1.10. [3] Misallkan $\alpha, \beta \in \operatorname{Sym}(S)$. Jika $F_{\alpha} \cup F_{\beta}=S$, maka $\alpha \beta=\beta \alpha$.

Bukti. Diketahui $F_{\alpha} \cup F_{\beta}=S$, berarti $S-\left(F_{\alpha} \cup F_{\beta}\right)=\emptyset$ atau $\left(S-F_{\alpha}\right) \cap\left(S-F_{\beta}\right)=\emptyset$. Menurut Proposisi 1.2, $T_{\alpha}=S-F_{\alpha}$ dan $T_{\beta}=S-F_{\beta}$ berarti $T_{\alpha} \cap T_{\beta}=\emptyset$. Karena $T_{\alpha} \cap T_{\beta}=\emptyset$, berdasarkan Definisi 1.7, maka $\alpha$ dan $\beta$ disjoint. Selanjutnya, berdasarkan Teorema 1.8 hal ini berarti $\alpha \beta=\beta \alpha$.

\section{Ucapan Terima kasih}

Penulis mengucapkan terima kasih kepada Bapak Dr. Admi Nazra, Ibu Nova Noliza Bakar, M.Si, Ibu Dr. Lyra Yulianti, Ibu Dr. Yanita dan Bapak Zulakmal, M.Si yang telah memberikan masukan dan saran sehingga tulisan ini dapat diselesaikan dengan baik.

\section{Daftar Pustaka}

[1] Gallian, J.A. 2006. Contemporary Abstract Algebra, Seventh Edition. Brook/Cole, Cengange Learning, Australia

[2] Paley, H dan P.M. Weichsel. 1996. A First Course in Abstract Algebra. Holt, Rinehalt and Winston Inc, New York

[3] Winton, Ricard. 2010. Commutativity in Permutation Grups, (Online),(http:// MSME.com). Diakses Senin 25 Juni 2012 